\title{
La difusión de la moda en la era de la globalización
}

\section{Ana Martínez Barreiro}

Universidad de La Coruña. Facultad de Sociología

anamb@udc.es

\section{Resumen}

Este trabajo se propone investigar cómo, tras el impacto de la globalización, se hace necesario abordar el tema de la difusión de la moda desde una perspectiva diferente. Sobre todo, se hace preciso examinar si el modelo de «filtrado descendente» mantiene su vigencia o si, por el contrario, le sustituyen con ventaja otros modelos que aparecen tras el impacto de la globalización económica y cultural.

Palabras clave: globalización, modelos de difusión, estilo subcultura, moda y tribalismo.

\section{Abstract. The diffusion of fashion after the impact of globalization}

This study proposes investigating how, after the impact of globalization, it is necessary to deal with the question of the diffusion of fashion from a different perspective; in particular, it is necessary to explore if the model of «descending filtration» is still valid, or if, on the contrary, it is superseded by other models that appear after the impact of economic and cultural globalization.

Key words: globalization, diffusion models, subculture style, fashion and tribalism.

\section{Sumario}

Introducción 3. La cultura postmoderna certifica la globalización de la moda

1. Los modelos de difusión de la moda

2. El impacto de la globalización 4. Conclusiones económica Bibliografía

\section{Introducción $^{1}$}

La globalización económica ha introducido cambios significativos en la producción, distribución y tambien en la comunicación en todas sus formas. Asimismo, los efectos de la globalización se sienten en el ámbito personal,

1. Esta investigación es fruto de un proyecto de investigación financiado por la Xunta de Galicia y del que ya me ocupé con anterioridad en extenso en una publicación de la RIS (2004), n. ${ }^{\circ} 39$ : 139-166. 
incluso sobre las opciones que tomamos en nuestra vida cotidiana - como lo que nos ponemos- que forman parte del proceso de creación de nuestra propia identidad. Todas estas transformaciones nos están obligando a redefinir la validez de los modelos de difusión de la moda en las sociedades postmodernas. La hipótesis central de esta investigación consiste en cuestionar el modelo de "filtrado descendente" y argumentar la validez del modelo de la «virulencia» tras el impacto de la globalización económica y cultural. Este artículo consta de tres partes. Tras la presentación del marco conceptual de los tres modelos más aceptados de difusión de la moda, se examinan los cambios que trae consigo el paso de la producción en serie a la producción flexible en el sector textil y de la confección que nos llevan a superar la visión del «filtrado descendente». Finalmente, se analizan las condiciones en que la globalización cultural nos enfrenta a un nuevo individualismo multicultural, esto es, a la estética como expresión del ambiente tribal. Esta última consideración nos invita a reconsiderar los modelos de referencia, ante las condiciones de la globalización, y a afirmar que las nuevas modas se propagan como el sida y las epidemias.

\section{Los modelos de difusión de la moda}

Hoy en día, las imágenes, los artículos y los estilos se crean y se dispersan por el mundo con mucha mayor rapidez que nunca, gracias al comercio internacional, a las nuevas tecnologías de la información, a los medios de comunicación internacional y a la emigración global. De alguna forma, todos estos factores han contribuido con éxito a que las modas tengan tal libertad de movimientos que se les permite cruzar fronteras con facilidad. La globalización ha cambiado fundamentalmente el carácter de nuestra experiencia cotidiana; por consiguiente, se hace necesario también abordar el tema de la difusión de la moda desde una perspectiva diferente; sobre todo se hace preciso examinar si el modelo de «filtrado descendente» mantiene su vigencia o si, por el contrario, le sustituyen con ventaja otros modelos que aparecen tras el impacto de la globalización. Uno de los principales interrogantes en torno a la difusión cultural de la moda es el camino que ella sigue en su itinerario social. A este interrogante, la sociología moderna ha dado dos respuestas: según la primera, las innovaciones en el campo de la moda y de los consumos en general se dirigen esencialmente a las clases superiores para difundirse en sentido vertical desde las clases más altas a las bajas; esto valdría para las sociedades preconsumistas, investigadas por Veblen (1974), pero también para las consumistas, investigadas por Baudrillard (1974) y Bourdieu (1991), al tratarse de fenómenos dependientes de la estructura de clase en la sociedad capitalista. Este fenómeno se conoce también con la denominación trickle-down effect ${ }^{2}$; se trata de un mecanismo que permite la difusión "gota a gota» de las modas, de los

2. Este modelo es empleado por el sociólogo Wiswede (1971: 87). 
nuevos estilos de vida y del consumo en general, por el efecto que sobre los comportamientos tiene el sistema jerárquico de los estatus.

Otra de las respuestas pone de manifiesto que, dentro de las sociedades de masas, las innovaciones ya no tienen sólo como referencia a las elites, sino también a las clases medias: las auténticas innovadoras y protagonistas de la vida económica contemporánea. Y, partiendo de este centro propulsor, las modas culturales se difunden tanto hacia arriba como hacia abajo en la jerarquía social. En este contexto de una mayor democratización de los procesos económicos y culturales, surge la perspectiva pluralista de los modelos de difusión que nos aportan Ragone (1986), Konig (1972), Katz y Lazarsfeld (1970) y otros, considerando que los consumos innovadores nacen ahora en una zona intermedia o mercado medio, sustrayéndose del mecanismo de innovaciones que era típico del periodo anterior, en el cual las modas se formaban en las zonas de altos ingresos, para trasladarse después, por un fenómeno de atracción, al nivel de masas. De acuerdo con esta última postura, Wiswede (1971) propone el modelo de la "virulencia». La palabra virulencia, en castellano, alude al poder que tienen las bacterias para reproducirse y segregar sustancias tóxicas y que transmiten a otros seres. Por consiguiente, se trata de un esquema de difusión de la moda "por contagio" y de una forma de propagación como la del sida o las epidemias.

En los últimos años, se ha observado un gran interés científico por los procesos de contagio en la moda o en la difusión cultural. El hito indiscutible de este nuevo campo de estudio llamado memética es Richard Dawkins (2000), que introduce el concepto de meme. Un meme es la unidad mínima de transmisión cultural. Una canción o una moda como la minifalda en los años setenta o el piercing en los años noventa pueden ser considerados memes, como los virus informáticos o una idea cientifica. Susan Blackmore (2000), desde la perspectiva semiótica, introduce la distinción entre los memes basados en la reproducción de un producto (copy the product) y los memes basados en la difusión de instrucciones (copy the instruction). La memética se presenta como una perspectiva aplicable a cualquier fenómeno cultural y, por consiguiente, a los fenómenos de difusión y a las modas.

Lipovetsky (1990) se cuestiona también el modelo de la transmisión vertical. A su juicio, con el surgimiento de la sociedad abierta, se inicia un nuevo régimen de difusión en la moda. La ley de imitación vertical es sustituida por la imitación horizontal. El modelo piramidal donde los artículos nuevos se difunden a partir de las clases superiores e invaden paulatinamente a las clases inferiores ya no es válido o pertinente en sentido global. Con el surgimiento del prêta-porter se vaticina el final del dirigismo disciplinario de la apariencia y la aparición de la multiplicidad estética. Ya no hay una «sola moda», sino «una multiplicidad de modas» igualmente legítimas (Lipovetsky, 1990: 119-171). Con esa fragmentación estilística, se producen otros cambios muy significativos. En primer lugar, se constata una mayor autonomía de los consumidores en relación con las novedades. Mientras en la fase anterior había que adoptar los últimos modelos lo más rápidamente posible, en la actualidad, por el con- 
trario, la tendencia es meramente indicativa. Ya no hay una correspondencia entre la innovación y la difusión, entre la vanguardia creativa y el público consumidor, pues "la calle se ha emancipado» de la fascinación de los líderes de la moda y asimila las novedades a su ritmo y a su antojo. En segundo lugar, "el look funciona a la carta» (1990: 161). Las mujeres continúan siguiendo la moda, pero de manera más libre. Llevan lo que les gusta, lo que les va, no la moda por la moda. El mimetismo directivo característico de la moda clásica ha dado paso a un mimetismo de tipo optativo. Se imita lo que se quiere, cuando se quiere y como se quiere. En tercer lugar, la moda entra en la era desapasionada del consumo, en la era de la curiosidad relajada y diversificada. La lógica cool ha invadido el espacio de la moda. En cuarto lugar, otro de los efectos más importantes del individualismo contemporáneo respecto a la moda es que ha reducido el símbolo jerárquico en favor del placer, la comodidad y la libertad, pues a través del vestido ya no se busca prioritariamente hacer alarde de pertenencia a una clase social, sino de un gusto, de un estilo de vida, pasando del estatus simbolo al estilo símbolo. Los análisis de la sociología moderna, representada hoy por Bourdieu y Baudrillard, parecen haber olvidado una parte esencial de la explicación de la moda contemporánea, al haber permanecido ciegos a un nuevo tipo de regulación social cuya base es la seducción individual y estética (Lipovesky, 1990: 170). De ahí la vigencia del modelo de la virulencia: mimetismo horizontalmente inducido por contagio mediante su difusión capilar a través de las superficies de contacto entre los grupos de pares o iguales, y que comparten el mismo estrato social.

La teoría del filtrado descendente ha sido criticada por Rouse (1989), según el cual si la teoría de filtración descendente depende del intervalo de tiempo entre el momento en que las modas se adoptan por la elite y aquél en que llegan a ser adoptadas por las clases más bajas, esta postura ya no es aplicable en las sociedades postmodernas, porque, dado el volumen de producción actual y la creciente globalización de la producción y el masificado consumo, ese intervalo de tiempo prácticamente ha desaparecido. Braham (1997), por su parte, considera que la «alta costura» como innovadora principal ha perdido importancia en la moda contemporánea, pues las grandes firmas de moda han conseguido borrar la línea divisoria entre la "alta costura» y la "moda de la calle», tal como puede observarse en el amplio número de franquicias de estas firmas de moda que operan a escala mundial. De igual modo, el cambio vestimentario no tiene lugar porque las clases inferiores lleven las ropas de los ricos (propio en la sociedad preconsumista de Veblen), sino porque, en numerosas ocasiones, la clase trabajadora y otros grupos sociales influyen en sentido inverso y se convierten en modelos de referencia.

A partir de lo expuesto, el sociólogo Squicciarino (1990: 166) añade otro modelo que él define como el de las marionetas o Trickle-effect perfeccionado. Este último modelo pone de manifiesto que en las sociedades de consumo maduro, aunque se dé una mejora general del nivel de vida, subsiste, a pesar de las apariencias, una relación piramidal disfrazada entre las clases sociales, en las que, de forma oculta y a través de los medios de comunicación de masas, se 
sugiere constantemente a las clases inferiores modelos de comportamiento con un esquema del tipo "consumo-dependencia». Cuanto más se dé el bombardeo publicitario del consumo, más alta será la posibilidad de que las masas sean «manipuladas» y «engañadas» por los hilos invisibles del poder económico. En la misma línea, Baudrillard (1974) afirma que ningun objeto de consumo emerge espontáneamente del consumidor básico si antes no aparece en el select package 3 de las necesidades. El consumo de objetos se filtra hacia abajo en virtud de un principio absoluto: «la conservación de las distancias a través del sistema de signos» (op. cit., 1974: 75). De ahí que las necesidades de las clases medias están siempre sujetas a aparecer con una cierta distancia en el tiempo en relación a las de las clases superiores. Al parecer, ésta era una de las formas más frecuentes de segregación en la sociedad de consumo de masas. Por su parte, Bourdieu (1991) considera que el error inherente al modelo del trickledown effect reside en el hecho de reducir a una búsqueda intencional de la distinción lo que en realidad es un efecto objetivo y automático de las condiciones de los consumidores y de la diferenciación de la producción en las sociedades contemporáneas (1991: 224).

La exposición anterior nos sugiere que, para comprender la moda, es necesario trascender el argumento del itinerario social, puesto que lo que se define y reconoce como «moda» es el producto de una cadena de actividades industriales, económicas y culturales. Lo que distingue el código de la moda es que ha de pasar por el filtro de la industria de la moda, de manera que las modificaciones del código presentadas en las pasarelas se exponen a ser rechazadas por una serie de publicistas y periodistas de la moda, pero también por los fabricantes y los compradores. En la actualidad, numerosos autores como Fine y Leopold (1993), al igual que Braham (1977), arguyen que la moda no es sólo cultura, sino también industria; no trata sólo del consumo, sino también de la producción. Por consiguiente, para comprender el funcionamiento del sistema de la moda, hemos de apartarnos del modelo de "filtrado descendente» que ha supuesto la base de muchas discusiones sobre la moda y su difusión y contemplar la moda como resultado de procesos socioeconómicos más complejos tras el desarrollo de la sociedad de consumo y el impacto de la globalización económica y cultural.

\section{El impacto de la globalización económica}

En las últimas décadas, ha surgido una nueva economía a escala mundial, esto es, la economía informacional y global. Es informacional porque la productividad y la competitividad de las unidades o agentes de esta economía (ya sean empresas, regiones o naciones) dependen de su capacidad para generar, procesar y aplicar la información con eficiencia. Y es global porque la producción,

3. Standard package, según Riesman: conjunto de bienes y servicios que constituyen la especie de patrimonio clásico del americano medio. Select package, idéntico significado, salvo que referido a las elites sociales. 
el consumo y la circulación, así como sus componentes (capital, mano de obra, materias primas, gestión, información, tecnología, mercados) están organizados a escala global. En lo que sigue, trataremos de conocer y comparar el sector textil y de la confección, explicar el conjunto de dispositivos organizativos que existen en el sector y, finalmente, observar la relación entre economía y cultura.

Se ha dicho que las empresas de la confección textil presentan una existencia efímera, puesto que están continuamente reemplazadas unas por otras (Singleton, 2000). La dificultad de mantener la ventaja competitiva - por ejemplo, el bajo coste del empleo - ha hecho modificar la estructura internacional del sector, de modo que sociedades que hace sólo unos lustros eran pioneras en la exportación, ahora no resultan más que meras caricaturas de lo que en algún momento fueron, y eso en el caso de que aún no hayan desaparecido del mercado. Pero también es cierto que firmas que hace sólo treinta años no eran más que modestos negocios, donde fabricantes y distribuidores eran los propios componentes de la unidad familiar, constituyen en la actualidad lo que en el argot empresarial se califica como killers y siguen gozando de excelente salud. El mapa actual de la confección textil global no tiene nada que ver ya con el de hace veinte años, ni en el tamaño de las empresas, ni en los nombres de las sociedades que lideran el sector, ni en el volumen generado por sus exportaciones, ni en los países donde asientan sus sedes. El más significativo de los actuales killers de la confección, la firma norteamericana Gap, fue creado por dos desconocidos, Don y Doris Fisher, en San Francisco en 1969. Lo mismo sucede con Ann Taylor, la diseñadora de moda femenina, cuyos orígenes datan de 1954, cuando abrió su tienda en New Haven. The Limited fue creada en 1963 en la localidad de Columbus (Ohio). La suiza Charles Vögele es sólo un poco anterior, de 1955, y la británica Next data de una fecha muy reciente (1982), aunque no tanto como la española Mango (1987). Por supuesto que no todos los killers disfrutan de semejante juventud. En algunos casos, proceden de algo más atrás (la norteamericana Abercrombie \& Fitsh, la italiana Benetton, la holandesa C\&A, la sueca Hennes \& Mauritz), pero, en realidad, han comenzando a operar como líderes a partir de las décadas de 1970 y 1980 (y algunas, como C\&A o Marks \& Spencer, no han podido soportar la durísima competencia y han visto reducidos sustancialmente sus mercados en los últimos tiempos). Otro caso es el del grupo Diseño Textil, S.A. (Inditex), más conocido por Zara, que, de vender confección doméstica en el mercado local durante la década de 1960, ha pasado a diseñar, producir y distribuir todo tipo de prendas de vestir y complementos para el consumo de masas en treinta y tres países — en tres continentes_-, compitiendo ventajosamente con líderes como la estadounidense Gap o la sueca Hennes \& Mauritz, y superando a otras que hasta no hace mucho se situaban entre las más relevantes.

A continuación, trataremos de dar cuenta del conjunto de dispositivos organizativos que existen en la economía informacional y que afectan al sector de la industria textil y de la confección. Todos estos avances, incluyendo la creciente globalización de la producción y el consumo, han sido bautizados 
bajo la rúbrica de postfordismo o producción flexible. La reestructuración económica de la década de 1980 indujo diversas estrategias de reorganización en las firmas comerciales. Algunos analistas, en particular Piore y Sabel (1990), sostienen que la crisis económica de los años setenta fue el resultado del agotamiento del sistema de producción en serie y constituyó una segunda revolución industrial en la historia del capitalismo. Algunos, como Coriat (1994), sugieren una evolución a largo plazo del fordismo al postfordismo, como expresión de una gran «transición»: la transformación histórica de la relación entre producción y productividad, por una parte, y entre consumo y competencia, por otra. Pero, a pesar de la diversidad de planteamientos, existe coincidencia en varios puntos fundamentales del análisis.

La primera y más amplia tendencia de la evolución organizativa que se ha identificado es «la transición de la producción en serie a la producción flexible». Cuando la demanda se volvió impredecible en cantidad y calidad, cuando los mercados se diversificaron en todo el mundo, y cuando el ritmo del cambio tecnológico hizo obsoleto el equipo de producción de cometido único, el sistema de producción en serie se volvió demasiado rígido y costoso para las características de la nueva economía. Para superar esa rigidez, surge la producción flexible o especialización flexible, que, gracias al diseño por ordenador, junto con otros tipos de tecnologías informaticas, ha cambiado radicalmente la situación anterior: ahora se trata de producir cantidades de productos menores y más individualizados que con los procesos de producción masivos. A su vez, las nuevas tecnologías permiten la transformación de las cadenas de montaje características de las grandes empresas en unidades de producción fáciles de programar, que pueden ser sensibles a las variaciones del mercado (flexibilidad del producto) y a los cambios de los insumos tecnológicos (flexibilidad del proceso).

En el sector existen varias modalidades de integración: la predominante, que incluye únicamente los procesos de diseño y comercialización (Gap, Hennes $\&$ Mauritz, Abercrombie \& Fitch, Ann Taylor, The Limited, Next, Charles Vögele), pero deja fuera la fabricación, que se subcontrata a otras sociedades (en muchos casos de actividad sumergida o de países asiáticos donde no existe reglamentación laboral), y el modelo Benetton (Benetton, Mango), que integra los procesos de diseño y fabricación, pero la comercialización se realiza al por mayor a través de franquicias y sólo raramente por medio de joint ventures o tiendas propias ${ }^{4}$. El modelo Inditex constituye la suma de los dos casos anteriores, aunque en grado diferente. Inditex actúa mediante un modelo integrado desde el diseño, el aprovisionamiento de materias primas (el $40 \%$ interno), la producción (en un $40-50 \%$ de producción propia), la red logística y

4. En la confección textil, no existe aún el modelo Nike, que mantiene tan sólo el diseño, sin integrar la fabricación ni la distribución. Véanse Jesús M. Valdaliso y Santiago López (2000: 279), quienes toman las referencias de M. T. Donaghu y R. Barff (1990), «Nike just did it: International Subcontracting and Flexibility in Athletic Footwear Production", Regional Studies, 24, 6: 537-552. 
las tiendas (92\% propias) (Castellanos, 2004: 9-11). La utilización generalizada del sistema de subcontratación, tanto en los países en desarrollo como en los desarrollados, constituye uno de los factores que proporcionan flexibilidad a las empresas textiles, en cuanto permite ampliar o reducir la escala de la producción en función de las oportunidades del mercado, pero comporta efectos sociales que son vistos por algunos como indeseables 5 .

Otra de las ventajas de la producción flexible es el modelo just in time, basado en pequeñas cadenas independientes y que permite modificar sobre la marcha la producción y adaptarla a los cambios observados en la demanda. De hecho, en el sector de la confección, que es el que sostiene el paradigma de la moda, y en el que las preferencias de los consumidores son tan variables, resulta fundamental efectuar estos cambios en la clásica cadena, porque son los que dan flexibilidad al conjunto. Por consiguiente, la flexibilidad ha sido acrecentada gracias al sistema de JIT, pues, además, permite ordenar los datos sobre las ventas entre fabricantes y minoristas y permite operar con niveles de inventario mínimos. La creciente importancia de seguir el ritmo de la moda condujo a hacer hincapié en partidas más pequeñas para reducir el riesgo de superávit. La producción se lleva a cabo, en la medida de lo posible, basándose sólo en pedidos firmes de minoristas. Esta flexibilidad ha sido acrecentada en los últimos años, a través de un depurado sistema informático que comunica, en tiempo real, la caja realizada, los artículos que se venden, las tallas más solicitadas en los establecimientos, etc. La rapidez de acceso de las prendas al mercado incrementa doblemente la flexibilidad en un sector de bienes tan efímeros.

Otra de las características del sistema de la producción textil es la diversificación de la oferta en función de las características del mercado. Se trata de una estrategia que aplican muchas firmas y que ha favorecido la expansión en las últimas décadas. Aquellas sociedades que no producen para un mercado segmentado, acaban acusándolo en la cuenta de resultados (C\&A, Marks \&Spencer). El marketing de nicho que surgió en los años ochenta consiste en producir para un mercado de consumidores muy segmentados según distintas variables, como la identidad, la edad, el capital económico y el gusto, entre otras. Los nichos de mercado describe «agrupaciones afectivas que emergen a través de unos sistemas compartidos de códigos simbólicos, como el adorno, el gusto y el habitus» (Shields, 1992: 14). En España, el grupo Inditex ha sido una de las primeras firmas del sector en incorporarla, aunque la innovadora, en este caso, fue la

5. Sobre estas cuestiones, puede consultarse la página web de la organización no gubernamental Setem (http://www.pangea.org/ropalimpia), que, a través de la campaña «Ropa limpia», ha logrado sensibilizar a la opinión pública europea. En este sentido, uno de los últimos informes sobre el textil de la Organización Internacional del Trabajo (La práctica laboral de las industrias del calzado, el cuero, los textiles y el vestido, Ginebra, OIT, 2000), señalaba que la globalización económica había estimulado a las multinacionales a deslocalizar la fase de confección, trasladándola a países y áreas deprimidas, en donde los costes de empleo se manifestaban muy inferiores. 
firma americana Gap. Inditex ha creado cinco marcas de comercialización bien diferenciadas.

El ajustado conocimiento de las preferencias de los consumidores se obtiene por una triple vía: en primer lugar, a partir de la información que proporcionan las pasarelas internacionales y los grandes modistos; en segundo lugar, a través de los equipos de informadores que recorren los ambientes frecuentados por los consumidores potenciales (discotecas, universidades, sitios de ocio); en tercer lugar, y muy importante, por medio de la información que transmiten los vendedores de las tiendas o los puntos de venta. Toda esta información se procesa y se envía a los departamentos de diseño y de allí a la producción. Esto permite conocer, en tiempo real y con unos costes bajos, los artículos, las tallas, los diseños, los colores más solicitados y adaptar el producto a la demanda real (Alonso Álvarez, 2000). El crecimiento del consumo y la fragmentación del gusto ha alterado sutilmente el modo en que se produce, se distribuye, se comercializa y se vende la moda. Esto ha servido para crear significados en torno a los artículos, hasta el punto de que lo que se consume es la imagen, no el objeto en sí. El expandido mercado de imágenes sobre la industria de la moda ha creado la necesidad de una nueva fuerza laboral de creadores de imágenes y, una vez más, los intermediarios culturales entran en escena para desempeñar su función.

Conocidas sus preferencias y satisfechas eficazmente en términos de producto, se trata de buscar la fidelización de los clientes. La norteamericana Gap y la sueca H\&M lo hacen, por ejemplo, a través de la propaganda directa en los medios de comunicación de masas, y gastan anualmente un $5 \%$ y un $4 \%$ de sus ingresos en publicidad. El promedio de las firmas del sector se sitúa en un $3,5 \%$ (Inditex). Por el contrario, Zara sólo destina a ello un $0,3 \%$, porque considera este tipo de mercadotecnia muy poco eficiente, en tanto que el resultado obtenido no compensa las inversiones realizadas. Por ello, esta empresa nunca se anuncia a sí misma, salvo las dos veces prescriptivas que imponen las rebajas estacionales, y aun entonces lo realiza de una manera elemental y discreta. Inditex se sitúa así en las antípodas de Benetton y sus campañas de publicidad salvajes. La tienda es, para Inditex, un factor básico, a estos efectos, debe estar en la principal ciudad, en la mejor zona, en la calle más comercial y en la esquina más atractiva. Desde hace algunos años, se ha instaurado un nuevo tipo de marketing que afirma explícitamente su preocupación por los valores éticos y posiciona las marcas y los productos sobre una base moral. Ha llegado la hora del «marketing de la solidaridad», de la empresa ciudadana (Lipovetsky, 2003: 68). En este sentido, por ejemplo, el grupo Benetton se ha interesado en construir su imagen de marca basándose en el antirracismo y el llamamiento a la tolerancia. Se trata de crear por esa vía una buena imagen corporativa ante los consumidores, algo que se está convirtiendo en un nuevo factor de competitividad.

Por lo que respecta a la expansión en el mercado internacional, está impregnada también de esa estrategia flexible de la que hablaba más atrás. La mayoría de las firmas del sector se expansionan de manera selectiva a través de fran- 
quicias, joint-ventures o filiales, independientemente de los países a donde acuden. En suma, lo que tienen en común los líderes mundiales de la industria textil de la confección, no es sólo una breve historia y una salida reciente al mercado internacional, sino que les unen una cultura empresarial y un apoyo en una mercadotecnia sofisticada, que aprovecha internamente las mayores ventajas que les proporciona una economía cada vez más internacionalizada.

\section{La cultura postmoderna certifica la globlalización de la moda}

\subsection{Moda y cultura}

Tal como se desprende de lo anterior, la moda es el resultado de una serie de prácticas interconectadas: prácticas de mercado y económicas, desarrollos tecnológicos y una serie de prácticas más culturales, como el marketing y el diseño. Hasta hace nada, los conceptos de "negocio" y "cultura» eran incompatibles. No obstante, a partir de los años ochenta, la conexión entre negocio y cultura es un medio esencial para asegurar el éxito empresarial. En la actualidad, se emplea el termino «economía cultural» para describir el modo en que la cultura y la economía se relacionan de una forma tan compleja que ninguna esfera determina a la otra. Ninguna actividad es puramente económica, todas las decisiones económicas implican otras de carácter más cultural. La cultura está, a su vez, afectada por manifestaciones y decisiones económicas. El significado cultural es creado con frecuencia en lugares económicos, en el trabajo y en las tiendas. Desde esta perspectiva, podemos observar una serie de prácticas que vienen a aclarar más la relación entre economía y cultura cuando éstas se unen en la experiencia de los lugares de venta como las tiendas y los centros comerciales. Estos espacios anulan la diferencia entre lo cultural y lo económico, ya que comprar es tanto una actividad económica como cultural. Estos lugares no son sólo espacios para el consumo de artículos e imágenes, sino que desempeñan un papel esencial en la expresión de la identidad y de la subjetividad de la cultura postmoderna. El espacio nunca es inerte, sino que está activo en la constitución de las relaciones sociales. La organización espacial de las calles y los edificios produce un impacto en los movimientos de los cuerpos y organiza el flujo de las masas hacia ciertos tipos de actividades y de relaciones. Al parecer, el diseño, la luz, el mobiliario y los materiales que se emplean desempeñan un papel esencial en conjugar la producción con el consumo, al asociar los bienes y los servicios con significados culturales particulares y enfocados a los posibles compradores» (Du Gay, 1997: 5).

\subsection{Moda e Individualismo}

La globalización está cambiando el carácter de nuestra experiencia cotidiana. A medida que las sociedades en que vivimos sufren profundas transformaciones, las consolidadas instituciones que solían sostenerlas van quedando fuera de lugar. Esto esta obligando a realizar una redefinición de aspectos íntimos y per- 
sonales de nuestras vidas como la familia, los roles de género, la sexualidad, la identidad personal, nuestras interacciones con los demás y nuestra relación con el trabajo. La idea que tenemos de nosotros mismos y de nuestras conexiones con el resto de las personas se está alterando profundamente a través de la globalización. En las sociedades actuales, los individuos tienen más oportunidades que antes para configurar su propia vida. Hubo un tiempo en el que la tradición y la costumbre ejercían una acusada influencia en la vida de las personas. Factores como la clase social, el género, el origen étnico e incluso el credo religioso podrían cerrarles ciertas vías a los individuos y abrirles otras. Los «códigos sociales» que antes guiaban las opciones y las actividades de las personas se han relajado considerablemente. Los marcos de la identidad tradicional se están disolviendo y emergen nuevas pautas en este sentido. La globalización nos está obligando a vivir de una forma más abierta y reflexiva. Esto significa que estamos constantemente respondiendo al entorno cambiante que nos rodea y ajustándonos a él. Incluso las pequeñas opciones que tomamos en nuestra vida cotidiana (lo que nos ponemos, cómo empleamos el tiempo libre, de qué manera cuidamos la salud y el cuerpo) forman parte de un proceso continuado de creación y recreación de nuestra propia identidad.

Como consecuencia del individualismo contemporáneo, ha emergido una nueva línea de investigación que es definida como la perspectiva multicultural de la moda y que está representada fundamentalmente por Lipovetsky, Morace, Maffesoli y Stuar Hall. Tras la crisis de las utopías revolucionarias y la emergencia del individualismo, hay un desplazamiento del interés público a lo privado y un ensalzamiento de los valores asociados a éste último. Esta mudanza, que es definida por Lipovetsky como la «segunda revolución individualista» (Lipovetsky, 1986: 9), se traduce en el declive de la moral centrada en el deber y la transformación privada del individuo. En este sentido, los valores permisivos y hedonistas relevan a los valores disciplinarios y rigoristas, que eran dominantes en la cultura del industrialismo burgués hasta el desarrollo de la sociedad de consumo y la comunicación de masas. En efecto, el individualismo narcisista se convierte en el nuevo trasfondo moral de las sociedades contemporáneas. En el ámbito de la moda, uno de los cambios que testimonian la emergencia de personalidades narcisistas, propias del individualismo contemporáneo, es que, paralelamente a la apariencia legítima, aparecen nuevos comportamientos individuales y colectivos en ruptura con el momento anterior: Se pone fin al orden disciplinario de la apariencia y surge la aparición de la multiplicidad estética de la moda.

\subsection{Moda y tribalismo}

Frente al individualismo de Lipovetsky y el narcisismo de Lasch, surge otra corriente del pensamiento que cuestiona el papel exclusivo del yo y que realza la importancia de la extensibilidad del yo en tribus a las que se pertenece simultáneamente o sucesivamente. Ésta es la hipótesis que Maffesolí (1990) expone en su libro Los tiempos de las tribus, al asegurar que nuestro principio 
de siglo exhibe una sociabilidad caracterizada por una dialéctica constante entre la masificación creciente y el desarrollo de unos microgrupos llamados tribus. Esta idea de tribu hace que estemos entrando en un tipo de sociedad en el que va a dominar la idea de extensibilidad del yo, un ego que se pierde en la tribu. Cuando uno se viste de la misma manera que se viste su tribu, ya no tiene, propiamente hablando, un sólo ego: hay aquí un ego extensible. Cuando uno lleva el uniforme punk, o uno lleva el traje burgués de tres piezas, se pierde en su tribu; y si en otro momento del día lleva otro uniforme (cambia, por ejemplo, su traje de tres piezas por el tejano o por cualquier otro vestido de esport), entra en otra tribu. De ahí que haya algo de extensible en mi identidad, pues no soy únicamente estable, me pierdo mediante la idea de extensibilidad del yo.

Durante mucho tiempo, uno de los conceptos básicos que había caracterizado a la sociedad moderna era el concepto de separación, tal como ha sido formulado por la tradición sociológica francesa, Maffesolí piensa que este concepto de separación, de distinción, está superado y lo que se aplica a la modernidad es la integración emocional a través del paradigma estético. En este paradigma estético, la mezcolanza vestimentaria, los cabellos multicolores, la manera de reutilizar los vestidos retros tienen la función de cemento, de unirme a los otros. En este sentido, la apariencia, el retorno de la imagen a un primer plano, va a tener una función de tipo comunitario. Pero se trata de un sentimiento y de una experiencia compartida que hacen que sea siempre en el interior de un grupo donde yo experimente algo y donde tenga que expresarme. Esto le lleva a decir a Maffesolí, que no hay narcisismo en las sociedades postmodernas, sino más bien una especie de sujeto colectivo, una extensibilidad del yo, la cual aparece particularmente representada en especies de reagrupamientos de tipo puntual. Las grandes ciudades modernas nos ofrecen buenos ejemplos de estas agrupaciones, cuando observamos, en la vida cotidiana, la representación en público de la sucesión de clichés: jogging, punk, el look retro o la moda grunch, etc. Todo esto da buena cuenta de este proceso tribal, que es el proceso de la modernidad. De ahí la importancia de la apariencia, que, de modo internacional, se llama look.

Según Davis (1992), Finkelstein (1991) y Giddens (1991), vivimos en un mundo en el que las identidades ya no son estables y donde el anonimato de las grandes ciudades nos permite experimentar con nuestra imagen. El yo moderno cada vez es más consciente de sí mismo, lo que incluye la propia imagen, y es capaz de intervenir y actuar sobre ella. Las subculturas juveniles utilizan el estilo, la ropa, el cuerpo, la postura para crear su identidad de forma consciente, tanto para afirmar su afiliación al grupo como para diferenciarse de los que están fuera y dentro del mismo. La vestimenta nos abre nuevas posibilidades para enmarcar el yo, aunque sean temporales. El seguir las modas «abre, a la vez que recorta, la posibilidad del desarrollo individual del yo y de la cooperación social» (Wilson, 1985: 63). No obstante, la moda no produce soluciones simbólicas permanentes: sus símbolos son demasiado efímeros y su ambivalencia está demasiado afianzada. En el mundo moder- 
no, la indumentaria viene a desempeñar un papel importante en el modo en que hacemos frente a dicha ambivalencia. Por consiguiente, cuando hablamos de la individualidad y de la identidad y del papel desempeñado por la moda y el vestir, es importante reconocer que las identidades tienen un sentido social. El individuo puede querer "destacar», pero también quiere "encajar» dentro de un grupo.

Para investigar el vestir en la cultura contemporánea, hemos de examinar el "estilo subcultural» $e$ indagar de qué forma este estilo expresa una preocupación por la imitación y la diferenciación. Simmel (1988) sostiene que la distinción es un rasgo característico de la moda. No obstante, en la cultura contemporánea, ésta no se transmite por los linajes de clase, sino a través de un amplio plano de identidades sociales, donde las subculturas juveniles utilizan la ropa para señalar identidades distintas, entre ellos y entre la cultura principal (Clarke, 1992: 55). Comparten algo de su «cultura matriz», pero tratan de expresar sus propias preocupaciones e intereses a través de un estilo distintivo y unos patrones de vida diferentes, como se da entre las distintas tribus urbanas como los rockers, los skinheads, los punk y otras ${ }^{6}$. Tal como ha señalado el mismo Simmel (1988), la moda se basa en la tendencia contradictoria hacia la similitud. Esta característica también es visible en las subculturas juveniles, que se acogen al estilo para manifestar la clara identidad de los miembros que se encuentran dentro de ella, frente a los que están fuera. En este sentido, el estilo expresa el grado de compromiso con el grupo e indica a los que están fuera la oposición a los valores del momento. A este respecto, el estilo es el «tejido conectivo" que resulta de nuestro sentido de interconexión con grupos concretos, puesto que hace visible nuestro compromiso con una comunidad en particular (Wilson, 1985) y produce sus prácticas corporales y sus propias formas de hablar. Para Entwitle (2002), esto es una forma de capital subcultural. De cualquier manera, la mayoría de las subculturas juveniles han confiado en la ropa usada o pasada de moda para crear su propio estilo.

\subsection{Globalización versus homogeneización, fragmentación y convergencia cultural}

$\mathrm{Al}$ analizar el flujo de la cultura postmoderna y el consumo global, se observa que el intercambio de estos signos crea la posibilidad de "compartir identidades», por ser consumidores de las mismas mercancías, clientes de los mismos servicios, oyentes de los mismos mensajes y videntes de las mismas imágenes, entre personas que están alejadas en el tiempo y en el espacio (Hall, 1997: 621). Uno de los signos más emblemáticos son los tejanos o las zapatillas, que

6. Respecto a la teorización de las subculturas juveniles, cfr. Dick Hebdige (1979). Frith (1996) estudia el origen de los punk, McRobbie (1994) argumenta el estilo hippie, Clarke (1992) investiga a los skinhead, Wills $(1975,1978)$ estudia el «acople» entre los intereses principales de la subcultura juvenil y su indumentaria a través del concepto de la homología y, finalmente, Barker y Beezer (1994) profundizan sobre los estudios culturales. 
parecen ser un uniforme universal de la juventud occidental y oriental ${ }^{7}$. La vida social se ha vuelto mediatizada por un mercado global de estilos, de lugares y de imágenes. Gracias a los viajes y a los desplazamientos, nos estamos confrontando simultáneamente con diferentes identidades en un gigantesco supermercado cultural. Este fenómeno social se conoce con el término de homogeneización cultural. En ese marco, Lucrecia Escudero (2001) considera a los bolsos y accesorios se vuelven claves, por el hecho volverse en sí mismo portador de un valor de diferenciación y homogeneización cultural. No obstante, frente a la tendencia hacia la "homogeneización global», hay también una fascinación por lo local que provoca simultáneamente nuevas identificaciones, tanto locales como globales.

Un simple ejemplo puede ilustrar este punto con claridad. ¿Qué nos dice el éxito de la película Titanic sobre la globalización? Por una parte, el éxito de la película dice que la globalización es una forma de «imperialismo cultural» mediante el cual los valores, los estilos y las perspectivas del mundo occidental se extienden de forma tan agresiva que asfixian a todas las culturas nacionales. Por el contrario, hay otros que vinculan el proceso de globalización con una creciente diferenciación de las tradiciones y las manifestaciones culturales. Para éstos últimos, la sociedad global no se caracteriza por la homogeneidad cultural, sino por la enorme diversidad de culturas que proceden de exterior, y que se ofrece a las personas para que elijan una gama de opciones en cuanto a estilos de vida. No estamos presenciando una cultura global unificada, sino una fragmentación de las formas culturales (Baudrillard, 1988). Las identidades establecidas y las formas de vida arraigadas en las comunidades locales y culturales están dando paso a nuevos tipos de «identidades híbridas», compuestas por elementos procedentes de fuentes culturales contradictorias (Hall, 1992). De este modo, hoy en día, una persona de un ámbito urbano de Sudáfrica puede continuar estando muy influida por las tradiciones y las perspectivas culturales de sus raíces tribales, al mismo tiempo que adopta estilos y gustos cosmopolitas en su vestimenta y en sus actividades de tiempo libre, y todo conformado por fuerzas globalizadoras.

En efecto, el desarrollo del mercado mundial tiene consecuencias importantísimas para las culturas, las identidades y los modos de vida. La globalización del quehacer económico está acompañada de olas de transformación cultural, en el seno de un proceso denominado "globalización cultural». Se trata principalmente de la fabricación de símbolos culturales y de una realidad que se viene observando desde hace ya bastante tiempo. Una buena parte de la sociología ha adoptado, para este problema, una postura que se acerca bastante a la tesis de la «convergencia de la cultura global». Según dicha tesis, se está produciendo una paulatina universalización, en el sentido de unificación de

7. Los países asiáticos han sido objeto de una occidentalización de su moda. Invadidos por firmas multinacionales. Esta coyuntura de causas excepcionales, como la llaman Waquet y Laporte (1999: 104) refiriéndose a la explosión del comercio internacional de la moda en el mercado asiático. 
modos de vida, símbolos culturales y modos de conducta transnacionales. Tanto en Singapur, com en Madrid o en México se llevan los mismos vaqueros. En una palabra, la industria de la cultura global significa cada vez más la "convergencia» de símbolos culturales y de formas de vida. Bajo el discurso del mercado mundial subyace, según esta perspectiva, una utopía negativa, y es que está surgiendo un solo mundo, pero no como reconocimiento de la multiplicidad, pluralista y cosmopolita de uno mismo y del otro, sino más bien todo lo contrario, como un solo mundo mercantil.

\section{Conclusiones}

En lo que respecta a la hipótesis central de esta investigación, hemos podido constatar que, tras el impacto de la globalización, el modelo "gota a gota", a pesar de mantener su vigencia a través de ciertos artículos de lujo, es sustituido con ventaja por el modelo de la «virulencia» que aparece tras la generalización de la sociedad de consumo y el impacto de la globalización económica y cultural. En las sociedades postmodernas, la teoría del filtrado descendente ya no es aplicable, dado el volumen de producción actual y la creciente globalización de la producción y el consumo masificado, pues el intervalo de tiempo prácticamente ha desaparecido entre el momento en que las novedades son adoptadas por la elite y aquél en que llegan a ser adoptadas por las clases más bajas.

Por lo que respecta a la circulación planetaria de las modas, se ha podido apreciar que ésta se produce gracias al surgimiento de una nueva economía informacional y global. Este cambio ha traído consigo toda una serie de avances recientes en la producción textil y de la confección, como la aparición de la "producción flexible», apoyada por el despliegue de las nuevas tecnologías informáticas, y el modelo just in time, que han supuesto unas indiscutibles ventajas competitivas para el sistema de la moda en la actualidad.

Otra de las ventajas se encuentra en los soportes mediáticos, donde los productos culturales o las modas circulan de forma global y en grandes cantidades como en una red global. Por consiguiente, la difusión de las modas no existe como una fuerza o una idea abstracta, sino que se materializa mediante las acciones de distintos agentes — productores, periodistas, consumidores - y que se constituye por interacción mutua entre todos ellos.

Por otro lado, se ha podido constatar que la globalización del quehacer económico está acompañada de olas de transformación cultural, donde el yo moderno cada vez es más consciente de sí mismo, lo que incluye la propia imagen y poder actuar sobre ella, y donde la vestimenta nos abre nuevas posibilidades para enmarcar el yo, aunque sean temporales. La globalización cultural nos lleva hacia un nuevo individualismo multicultural: la estética como expresión del ambiente tribal. Al mismo tiempo, a través del flujo de la cultura postmoderna y el consumo global, se crea la posibilidad de "compartir identidades», puesto que personas que están alejadas en el tiempo y en el espacio son consumidoras de las mismas mercancías. 
Y, finalmente, cabe decir que la globalización hace un mundo global como una moda global que supera todas las barreras de clase y las fronteras nacionales. De ahí que, en las sociedades postmodernas, las modas se propagan como el sida, las epidemias y los virus informaticos.

\section{Bibliografía}

Alonso Álvarez, L. (2000). «Inditex-Zara: Vistiendo a tres continentes». En: OJEA, Fernando (coord.). Grandes empresas, grandes historias de Galicia. A Coruña: Voz de Galicia.

BARKER, M.; BEEZER, A. (1994). Introducción a los estudios culturales. Barcelona: Bosch. BAUDRILLARD, J. (1974). La sociedad de consumo: sus mitos, sus estructuras. Barcelona: Plaza \& Janés, p. 92-100.

Blackmore, Susan (2000). La máquina de los memes. Barcelona: Paidos. Bourdieu, P. (1991). La distinción. Madrid: Taurus.

BRAHAM. P. (1997). «Fashion: Unpacking a Culture Production». En: DU GaY, P. (comp.). Production of Culture, Cultures of Production. Londres: Sage.

Campbell, C. (1989). The Romantic Ethic and the Spirit of Modern Consumerism. Oxford: Basil Blackwell.

- (1993). «Understanding Traditional and Modern Patterns of Consumption in Eighteenth-Century England: A Character-Action Appoach». En: BREWER, J.; PORTER, R. (comps.). Consumption and the World of Good. Nueva York: Routledge.

- (1997). «When the Meaning is not a Message: A critique of the Consumption as Comunication Thesis». En: NAVA, M.; BlaKe, A.; MacRurY, I.; RichardS, B. (comps). Buy this Book: Studies in Advertising and Consumption. Londres: Routledge.

CASTELlS, M. (1997). La era de la información: Economía sociedad y cultura, vol. 1. Madrid: Alianza, p. 179-223.

Castellanos, J.M. (1993). "Una ventaja competitiva: el factor tiempo. El caso de inditex-Zara». Papeles de Economía Española, n. ${ }^{0} 56$, p. 402-404.

- (2004). «Entrevista a José M. Castellanos sobre Inditex». Epnoticias, p. 9-11.

Clarke, J.S.; Hall, T.; JeFFERSON; ROBERTS (1992). «Subcultures, Cultures and Class». En Bennett, T.; Martin, G.; MerCer, C.; Wollacott (comps.). Culture, Ideology and Social Process: A Reader. Milton Keynes, Open University Press.

CORIAT, Benjamin (1993). El taller y el robot: Ensayos sobre el fordismo y la producción en masa en la era electronica. Madrid: Siglo XXI.

- (1994). "Neither pre-nor post-fordism: an original and new of managing the labour process». En: Tetsuro, K.; STEVen, R. (eds.). Is Japanese Management Post-Fordism? Tokio: Mado-sha, p. 182 y s.

Craik, J. (1993). The Face of Fashion. Culture Studies on Fashion. Londres y Nueva York: Routledge.

DAWKINS, Richard (2000). El gen egoista: Las bases biológicas de nuestra conducta. Barcelona: Salvat Ciencia.

DAvIS, F. (1992). Fashion, Culture and Identity. Chicago: University of Chicago Press. Du GaY, P. (1997). Production of Culture, Cultures of Production. Londres: Sage.

ENTWISTLE, Joane (2002). El cuerpo y la moda. Barcelona: Paidos.

Escucero, L. (2001). "Lógicas en la representación de la moda». DeSignis, n. ${ }^{\circ} 1$. Barcelona: Gedisa, p. 103-119. 
Fine, B.; LEOPOLD, E. (1993). The world of consumption. Londres: Routledge.

Flavian Blanco; Polo Redondo (2000). «Inditex (1994-1999)». En: Munuera ALEMÁN, J.L.; RodríGUEZ ESCUDERO, A.I. Estrategias de marketing para un crecimiento rentable: Casos prácticos. Madrid: Esic Editores.

Finkelstein, J. (1991). The Fashinned Self. Cambridge: Polity Press.

FRITH, Simon (1996). «Music and Identity». En: Questions of Cultural Identity. Londres: Sage, p. 108-128.

GIDDENS, A. (1997). Modernidad e identidad del yo: El yo y la sociedad en la época contemporánea. Barcelona: Península.

HaLl, S. (1997). «The Question of Cultural Identities». En: Hall, S. y otros. Modernity: An introduction to Modern Society. Oxford: Blackwell.

Hebdige, D. (1979). Subculture. The meaning of Style. Londres: Methuen.

KATZ, E.; LAZARSFELD, P. (1970). La influencia personal: El individuo en el proceso de comunicación de masas. Barcelona: Hispano-europea.

KING. C. W. (1981). «Fashion adoption: a rebuttal to the Trickle Down Theory». En: Sproles, George B. (ed.). Perspectives of Fashion. Minneapolis: Burgess.

Konig, R. (1972). Sociología de la moda. Barcelona: A. Redondo editor.

LeOPOlD, E. (1992). «The Manufacture of the Fashion System». En: AsH, J.; WiLsON, E. (comps.). Chic Thrills. Londres: Pandora.

LipOVETSKY, G. (1990). El imperio de lo efimero: La moda y su destino en las sociedades modernas. Barcelona: Anagrama.

- (2003). Metamorfosis de la cultura liberal. Barcelona: Anagrama.

MAFFeSOlí, M. (1990). Los tiempos de las tribus: El declive del individualismo de la sociedad de masas. Barcelona: Icaria.

MARTíNEZ BARREIRO, A. (1998). Mirar y hacerse mirar: La moda en las sociedades modernas. Madrid: Tecnos.

- (1998). «La moda en las sociedades avanzadas». Papers, n. ${ }^{\circ}$ 54, p. 129-137.

- (2000). «¿Cómo configuran los españoles su vestuario? RIS, n. o 25, p. 77-98.

McCraken, G.D. (1985). The Tricklen. Down Theory Rehabilitaded. Nueva York: Lexington Book.

MCRoBBIE (1994). Post-modernism and popular culture. Londres: Routledge.

Margan Stanley; Dean Witter (1999). Retailers-General, Speciality Clothing. Londres y Nueva York: MSDW.

- (2000). Speciality Clothing Report. $21^{\text {st }}$ Century Strategy. Londres y Nueva York: MSDW.

Partington, A. (1992). «Popular Fashion and the Working-Class Affluence». En: Ash, J.; Wilson, E. (comps.). Chic Thrills: A Fashion Reader. Londres: Pandora. PiORE, M.; SABEL, J. y Charles F. (1990). La segunda ruptura industrial. Madrid: Alianza Universidad.

Polhemus, T. (1994). Streetstyle. Luton: Lennard.

Ragone, G. (1986). Sociología dei fenomeni di moda. Milán: Franco Angeli. ROUSE, E. (1989). Understanding Fashion. Londres: BSP Professional Books.

SHIELDS, R. (1992) (comp.). Lifestyle Shopping: The Subject of Consumtion. Londres: Routledge.

Simmel. G. (1988). Sobre la aventura: Ensayos filosóficos. Barcelona: Península.

Singleton, John (2000). The World Textile Industry. 2a ed. Londres y Nueva York: Routledge.

Slater, D.R. (1993). «Going Shopping:Markets, Crowds and Consumption». En: JENKS (comp.). Cultural reproduction. Londres: Routledge. 
- (1997). Cultural and modernity. Cambridge: Polity Press.

SQUICCIARINO, N. (1990). El vestido habla: Consideraciones psicosociológicas sobre la vestimenta. Madrid: Cátedra.

Spencer, H. (1974). Principios de sociología. Buenos Aires: Revista de Occidente. TARDE, G. (1991). Les lois d'imitation. París: Alcan.

Veblen, T. (1974). Teoría de la clase ociosa. México: Fondo de Cultura Económica. VERDU (2004). El estilo del mundo: La vida en el capitalismo de ficción. Barcelona: Anagrama.

WAQUET, D.; LAPORTE, M. (1999). La mode. París: PUF.

WISWEDE, G. (1971). «Theorien der Mode aus soziologischer Sicht», en Jabrbuch der Absatz und Verñbrauchsforschung, 1.

WiLSON , E. (1985). Adorned in Dreams: Fashion an Modernity. Londres: Virago. 